Article

\title{
Structural Validity of 'Santa Clara Strength of Religious Faith Questionnaire’ in Greek Sample
}

\author{
Maria Dianni ${ }^{1}$, Miltiadis Proios ${ }^{2, *}$ and Charilaos Kouthouris ${ }^{3}$ \\ 1 Department of Physical Education and Sport Science, Democritus University, TEFAA Komotini \\ 69100, Greece; E-Mail: mdianni@hotmail.gr \\ 2 Department of Physical Education and Sport Science, Aristotle University, TEFAA Thessaloniki, \\ 54124, Greece \\ 3 Department of Physical Education and Sport Science, University of Thessaly, TEFAA Trikala \\ 42100, Greece; E-Mail: kouthouris@pe.uth.gr \\ * Author to whom correspondence should be addressed; E-Mail: mproios@phed.auth.gr; \\ Tel.: +30-231-099-2472; Fax: +30-231-084-2267.
}

Received: 31 December 2013; in revised form: 25 January 2014 / Accepted: 28 January 2014 / Published: 26 February 2014

\begin{abstract}
The aim of the present study was to investigate the structural validity and reliability of the Santa Clara Strength of Religious Faith Questionnaire (SCSRFQ) instrument in the Greek population. One hundred and three individuals (men $n=45$, and women $\mathrm{n}=58$ ) participated in this study. Their age ranged from 17 to 86 years. More specifically, the study investigated the fit of both versions of SCSRFQ (10-item and 5-item). The results of the present study revealed that both versions have adequate fit and can be used by Greek researchers as a measure of strength of religious faith in the Greek population.
\end{abstract}

Keywords: SCSRFQ; structure validity; Greek sample

\section{Introduction}

Religious faith is a question that has aroused strong interest among scholars in at least the last two decades. Thus, for the purpose of studying specific topics, a number of instruments have been created; as can been seen in the literature which reports a vast number of measures of religiosity (see [1-3]). The Santa Clara Strength of Religious Faith Questionnaire (SCSRFQ; [4,5]) was one of the instruments developed. 
The SCSRFQ is a brief 10 items self-reporting measure assessing strength of religious faith and engagement suitable for use with multiple religious traditions, denominations, and perspectives [6]. It was developed as a unidimensional construct [4,5] and was supported as a unifactorial measure of religious faith [7]. The validity and reliability of SCSRFQ was further supported in a series of studies. More specifically, in these studies validity was assured by investigating two different types of validity: construct validity (exploratory and confirmatory factor analyses) (e.g., [4,7]) and criterion-related validity (convergent and discriminant) (e.g., [5,8,9]). The investigation of construct validity in studies also checked the internal consistency reliability of SCSRFQ. Plante and Boccaccini [4,5] established that SCSRFQ possessed a high level of internal consistency, with Cronbach's alphas ranging between .94 and .97 and split-half reliability correlations ranging between .90 and .96 .

Apart from the original version of the 10-item instrument scale, a brief version of the Santa Clara Strength of Religious Faith Questionnaire-Short Form (SCSRFQ-SF) with 5-items [10] was also developed. Storch, Roberti, Bravata and Storch [11] in their study supported the validity and reliability of SCSRFQ-SF.

Research using SCSRFQ that have been published in quality peer reviewed settings have used the scale primarily in medical and university settings [6]. Here it should be noted that the population used in these researches consisted mainly of undergraduate students and a few adults. Although SCSRFQ has been used in multiple populations, such as Ireland and Germany [6], there are however no references that this scale has been used in other languages apart from English.

The significance of the present study lies initially in the use of SCSRFQ in a population of strong cultural differences (full supremacy of the Orthodox Christian religion) in comparison to the one already applied and, further, in the fact that SCSRFQ is applied in a wide range of ages. Moreover, SCSRFQ is tested in a language other than English, namely Greek. Finally, the establishment of the applicability of SCSRFQ in the Greek language will help Greek researchers to expand their empirical studies on religiosity issues in the Greek population. The aim of the present study is to investigate the structure validity and reliability of the SCSRFQ instrument in the Greek language. More specifically, it will examine the applicability of both versions original (10-item) and short-form (5-item).

\section{Method}

\subsection{Participants}

Participants in this study numbered 103 individuals (men $n=45$, and women $n=58$ ). Their age ranged from 17 to 86 years $(M=42.01, S D=14.27)$.

\subsection{Procedures}

The sample used in this study lived in a city with a population of one million. The questionnaires were filled out in the absence of researchers. Specifically, the participants were members of several organizations (religious and social) and the questionnaires reached them through other members of these organizations. The distribution of questionnaires was done by members of each organization after receiving relevant information by the researchers. The filling out of the questionnaires was done at the premises of each organization. 


\subsection{Measure}

The Santa Clara Strength of Religious Faith Questionnaire (SCSRFQ) [4,5] is a 10-item self-reporting measure. The Santa Clara Strength of Religious Faith Questionnaire-Short Form [10], which is based on the 10-item SCSRFQ, is a 5-item scale. Standardized back-translation procedures were used to develop a Greek version (see Appendix) of the SCSRFQ and SCSRFQ-SF using three independent bilingual translators [12]. The back-translation procedure was repeated iteratively until the original and back-translated English version of the questionnaire was virtually identical. The SCSRFQ uses a 4-point Likert response format, ranging from (1) Strongly disagree to (4) Strongly agree. The SCSRFQ was found to have high internal reliability, with Cronbach's alphas ranging between .94 and .97 and split-half reliability correlations ranging between .90 and .96 .

\section{Results}

The aim of the present study was to validate the Santa Clara Strength of Religious Faith Questionnaire (SCSRFQ) and Santa Clara Strength of Religious Faith Questionnaire-Short Form (SCSRFQ-SF). This instrument was to be validated on the basis of three types of validity: Interrelations among the items, factor analyses (exploratory and confirmatory) and internal consistency reliability.

Descriptive statistics established that the mean strength of religious faith scores as assessed by the SCSRFQ was $28.3(S D=7.6)$ among the Greek sample. According to the authors of the questionnaire, this score seems to be relatively high.

\subsection{Interrelations among the SCSRFQ and SCSRFQ-SF Items}

If two tests are presumed to measure the same construct, a correlation between them is predicted [13]. In the present study, the interrelations among the items (questions) were estimated by factor analysis (Tables 1 and 2). All items of the SCSRFQ and SCSRFQ-SF were correlated with each other.

Table 1. Correlation Matrix for the 10 items of the Santa Clara Strength of Religious Faith Questionnaire.

\begin{tabular}{llllllllll}
\hline & $\mathbf{1}$ & $\mathbf{2}$ & $\mathbf{3}$ & $\mathbf{4}$ & $\mathbf{5}$ & $\mathbf{6}$ & $\mathbf{7}$ & $\mathbf{8}$ & $\mathbf{9}$ \\
\hline Q2 & .68 & - & - & - & - & - & - & - & - \\
Q3 & .63 & .70 & - & - & - & - & - & - & - \\
Q4 & .76 & .81 & .78 & - & - & - & - & - & - \\
Q5 & .62 & .74 & .62 & .75 & - & - & - & - & - \\
Q6 & .75 & .73 & .67 & .81 & .73 & - & - & - & - \\
Q7 & .76 & .74 & .71 & .80 & .69 & .80 & - & - & - \\
Q8 & .64 & .62 & .64 & .68 & .67 & .69 & .62 & - & - \\
Q9 & .65 & .75 & .69 & .71 & .66 & .64 & .73 & .55 & - \\
Q10 & .57 & .55 & .52 & .66 & .66 & .58 & .54 & .54 & .60 \\
\hline
\end{tabular}

Note: $p<.01$. 
Table 2. Correlation matrix for the 5 items of the Santa Clara Strength of Religious Faith Questionnaire-Short Form.

\begin{tabular}{lllll}
\hline & $\mathbf{1}$ & $\mathbf{2}$ & $\mathbf{3}$ & $\mathbf{4}$ \\
\hline Q2 & .81 & - & - & - \\
Q3 & .74 & .75 & - & - \\
Q4 & .62 & .68 & .67 & - \\
Q5 & .55 & .66 & .66 & .54 \\
\hline
\end{tabular}

\subsection{Factor Analysis (FA)}

Factor analyses are "intimately involved with questions of validity" ([14], p. 112). They are used to reveal the latent structure (dimensions) of a set of variables. Factor analyses reduce correlational data to a smaller number of factors, and thus they are "nondependent" procedures (i.e., they do not assume that a dependent variable is specified). In the present study, factor analyses were used to examine the structure of the SCSRFQ and SCSRFQ-SF. Specifically, both exploratory and confirmatory factor analyses were used.

\subsubsection{Exploratory Factor Analysis (EFA)}

Both the Bartlett test of thoroughness $\left(x^{2}(45)=839.88, p<.001 ; x^{2}(10)=320.57, p<.001\right)$ and the Kaiser-Meyer-Olkin measure of sampling adequacy $(\mathrm{KMO}=.941 ; \mathrm{KMO}=.856)$ indicated that factor analysis in both versions, SCSRFQ and SCSRFQ-SF respectively, was appropriate for the data [15]. Items loaded with more than .40 were considered as loaded with one factor [16]. Then, variants multicolinearity was examined by means of communalities [17]. One factor derived from the analysis. The factor loadings and communalities are presented in Tables 3 and 4.

Table 3. Factor Loadings and Communalities for the Santa Clara Strength of Religious Faith Questionnaire.

\begin{tabular}{lcc}
\hline & Factor loadings & $\mathbf{h}^{\mathbf{2}}$ \\
\hline 1. My religious faith is extremely important to me. & .84 & .71 \\
2. I pray daily. & .87 & .76 \\
3. I look to my faith as a source of inspiration. & .83 & .68 \\
4. I look to my faith as providing meaning and purpose in my life. & .92 & .85 \\
5. I consider myself active in my faith or church. & .85 & .72 \\
6. My faith is an important part of who I am as a person. & .88 & .78 \\
7. My relationship with God is extremely important to me. & .88 & .76 \\
8. I enjoy being around others who share my faith. & .79 & .62 \\
9. I look to my faith as a source of comfort. & .83 & .68 \\
10. My faith impacts many of my decisions. & .73 & .54 \\
Alpha coefficient (\% variance explained) & .95 & 71.06 \\
\hline
\end{tabular}


Table 4. Factor Loadings and Communalities for the Santa Clara Strength of Religious Faith Questionnaire-SF.

\begin{tabular}{clcc}
\hline & & Factor loadings & $\mathbf{h}^{2}$ \\
\hline 1. I pray daily. & .87 & .76 \\
2. I look to my faith as providing meaning and purpose in my life. & .91 & .84 \\
3. I consider myself active in my faith or church. & .89 & .80 \\
4. I enjoy being around others who share my faith. & .81 & .66 \\
5. My faith impacts many of my decisions. & .79 & .62 \\
Alpha coefficient (\% variance explained) & .91 & 73.61 \\
\hline
\end{tabular}

Note: One factor structure accounted for $71.34 \%$ of the variance.

\subsubsection{Confirmatory Factor Analysis (CFA)}

A confirmatory factor analysis was applied because there was a priori knowledge of the number of factors at the initial stages of the questionnaire development [15]. One-factor model was postulated in both questionnaires (Table 5). The models were tested using confirmatory maximum likelihood (ML) factor analyses parameter estimates in AMOS 17.0. In addition, the variance-covariance matrices were analyzed using latent variable software programs AMOS 17.0. CFAs were applied because of $a$ priori knowledge of the number of factors, that is, on the structure linking observed variables to latent factors at the initial stages of the questionnaire development [15]. The ML algorithm was selected because it resulted in accurate fit indexes with ordered-categorical data that violate the assumption of multivariate normality $[18,19]$. The ML algorithm is also a standard estimation technique with ordered-categorical data [20]. The multiple imputation method was used to address the issue of missing data in the present study [21]. The sample size in the present study was adequate to estimate the various models based on two criteria: (a) the total sample size was larger than 100; and (b) the ratio of the total sample size to the number of freely estimated parameters should be greater than 10:1 and approximating 20:1 [22].

Table 5. Goodness-of-fit indices of models tested.

\begin{tabular}{lcccccc}
\hline Models & $\mathbf{x}^{2}$ & $\boldsymbol{D f}$ & $\boldsymbol{p}$ & TLI & CFI & RMSEA \\
\hline One-factor 10-item & 53.5 & 35 & .05 & .97 & .98 & .07 \\
One-factor 5-item & 10.98 & 5 & .05 & .98 & .98 & .10 \\
\hline
\end{tabular}

Four measures of model fit are reported: $\mathrm{x}^{2}$, confirmatory fit index (CFI), Tucker-Lewis index (TLI), and root mean square error of approximation (RMSEA). According to Hu and Bentler [23], for CFI and TLI a cut-off value close to .90 and a cut-off value close to .60 for RMSEA are needed before stating a relative good fit between the observed data and the hypothesized model. Examination of the multiple fit indices on the first model (10-item) revealed that RMSEA was .07, indicating a relatively good model fit, and high similar to the CFI (.98) and TLI (.97), while the second model (5-item) revealed that RMSEA was .10, indicating a marginally good model fit, and high similar to the CFI (.98) and TLI (.98). 


\subsection{Internal Consistency Reliability}

Internal consistency refers to the interrelatedness of a set of items [24]. The internal consistency estimate (alpha reliability) [25] in the present study was computed separately for the two questionnaires. Both subscales had alphas above the recommended criterion of .70 (Tables 3 and 4).

\section{Discussion}

In the present study, the structural validity of the Santa Clara Strength of Religious Faith Questionnaire (original and short form) in a Greek sample was investigated. The results of this study confirmed the factoral structure of SCSRFQ among a sample from Greece aged 18-84 years old. That is, the one-factor model exhibited adequate fit statistics. Based on these findings, the unidimensional structure of both scales (SCSRFQ and SCSRFQ-SF) as provided by Plante and Boccaccini [4], and Plante et al. [10] can be supported.

The findings of the present study further supported the claim of the writers of the SCSRFQ that this instrument can be used in different cultures. Also, the use in this study of a sample of the general population reveals the applicability of SCSRFQ in a sample population other than medical and educational samples which have mainly been used until now. Furthermore, the inclusion of adults in this sample augments research in adult populations which has been lacking in the past. Finally, the finding of applicability of SCSRFQ in a Greek sample, written in the Greek language, further supports the applicability of this questionnaire in other languages too. However, this claim needs to be supported with findings from other studies.

Finally, it is concluded that SCSRFQ is: (a) a unidimensional scale; (b) that is reliable and valid; (c) can be used in a wide range of ages and in different languages; and (d) can be used by Greek researchers as a measure of strength of religious faith in the Greek population.

\section{Author Contributions}

This paper is based on a part of the first author's M.A. dissertation, and is primarily his work-both writing and collect of the data-with a contribution of about $60 \%$. The second author was supported the data analysis. The third author was the M.A. supervisor, and worked with the first author closely in the design, and writing up of the study.

\section{Conflicts of Interest}

The authors declare no conflict of interest.

\section{References}

1. Peter C. Hill, and Ralph W. Hood. Measures of Religiosity. Birmingham, Alabama: Religious Education Press, 1999.

2. Peter C. Hill, Katie J. Kopp, and Richard A. Bollinger. "A few good measures: Assessing religion and spirituality in relation to health." In Faith and Health: Psychological Perspectives. Edited by Thomas G. Plante and Allen C. Sherman. New York, NY: Guilford, 2007, pp. 381-402. 
3. Jo A. Tsang, and Michael E. McCullough. "Measuring religious constructs: A hierarchical approach to construct organization and scale selection." In Positive Psychological Assessment: A Handbook of Models and Measures. Edited by Shane J. Lopez and Charles R. Snyder. Washington, DC: American Psychological Association, 2003, pp. 345-60.

4. Thomas G. Plante, and Marcus T. Boccaccini. "The Santa Clara Strength of Religious Faith Questionnaire.” Pastoral Psychology 45 (1997): 375-87.

5. Thomas G. Plante, and Marcus T. Boccaccini. "Reliability and validity of the Santa Clara Strength of Religious Faith Questionnaire.” Pastoral Psychology 45 (1997): 429-37.

6. Thomas G. Plante. "The Santa Clara Strength of Religious Faith Questionnaire: Assessing Faith Engagement in a Brief and Nondenominational Manner." Religions 1 (2010): 3-8. doi:10.3390/rel1010003.

7. Christopher A. Lewis, Mark Shevlin, Conor McGuckin, and Marek Navratil. "The Santa Clara Strength of Religious Faith Questionnaire: Confirmatory Factor Analysis.” Pastoral Psychology 49, no. 5 (2001): 379-84.

8. Dustin A. Pardini, Thomas G. Plante, Allen C. Sherman, and Jamie E. Stump. "Religious faith and spirituality in substance abuse recovery determining the mental health benefits." Journal of Substance Abuse Treatment 19 (2000): 347-54.

9. Allen C. Sherman, Thomas G. Plante, Stephanie Simonton, Dawn Adams, Kaay Burris, and Casey Harbison. "Assessing religious faith in medical patients: Cross-validation of the Santa Clara Strength of Religious Faith Questionnaire.” Pastoral Psychology 48 (1999): 129-42.

10. Thomas G. Plante, Charlotte L. Vallaeys, Allen C. Sherman, and Kenneth A. Wallston. "The development of a brief version of the Santa Clara Strength of Religious Faith Questionnaire." Pastoral Psychology 50, no. 5 (2002): 359-68.

11. Eric A. Storch, Jonathan W. Roberti, Erica A. Bravata, and Jason B. Storch. "Strength of religious faith: A comparison of intercollegiate athletes and non-athletes." Pastoral Psychology 52, no. 6 (2004): 485-89.

12. Richard W. Brislin. "The wording and translation of research instruments." In Field Methods in Educational Research. Edited by Walter J. Lonner and John W. Berry. Newbury Park, CA: Sage, 1986, pp. 137-64.

13. Lee J. Cronbach, and Paul E. Meehl. "Construct validity in psychology tests." Psychological Bulletin 52 (1955): 281-302.

14. Jum Nunnally. Psychometric Theory, 2nd ed. New York, NY: McGraw-Hill, 1978.

15. James Stevens. Applied Multivariate Statistics for the Social Sciences. Mahwah, NJ: Lawrence Erlbaum, 1996.

16. Timothy R. Hinkin. "A review of scale development practices in the study of organizations." Journal of Management 21 (1995): 967-88.

17. Harry H. Harman. Modern Factor Analysis. Chicago, IL: The University of Chicago Press, 1976.

18. Susan R. Hutchinson, and Antonio Olmos. "Behavior of descriptive fit indices on confirmatory factor analysis using ordered categorical data." Structural Equation Modeling 5 (1998): 344-64.

19. Ulf H. Olsson, Tron Foss, Sigurd V. Troye, and Roy D. Howell. "The performance of ML, GLS and WLS estimation in structural equation modeling under conditions of misspecification and nonnormality." Structural Equation Modeling 7, no. 4 (2000): 557-95. 
20. Rick H. Hoyle, and A. T. Panter. "Writing about structural equation models." In Structural Equation Modeling: Concepts, Issues, and Applications. Edited by Rick H. Hoyle. Thousand Oaks, CA: Sage Publications, 1995, pp. 158-76.

21. Joseph L. Schafer, and John W. Graham. "Missing data: Our view of the state of the art." Psychological Methods 7, no. 2 (2002): 147-77.

22. Rex B. Kline. Principles and Practice of Structural Equation Modeling, 2nd ed. New York: The Guilford Press, 2005.

23. Li-tze $\mathrm{Hu}$, and Peter M. Bentler. "Cutoff criteria for fit indexes in covariances structure analysis: Conventional criteria versus new alternatives." Structural Equation Modeling 6 (1999): 1-55.

24. Neal Schmitt. "Uses and abuses of coefficient alpha." Psychological Assessment 8 (1996): 350-53.

25. Lee J. Cronbach. "Coefficient alpha and the internal structure of tests." Psychometrika 16 (1951): 296-334.

\section{Appendix}

Santa Clara Strength of Religious Faith Questionnaire (in Greek language)

1. Н

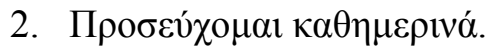

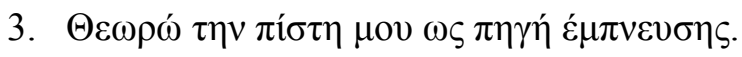

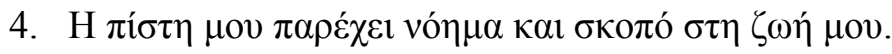

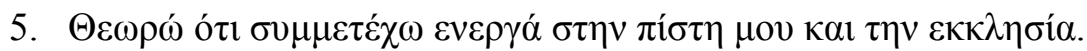

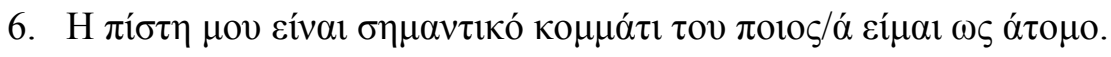

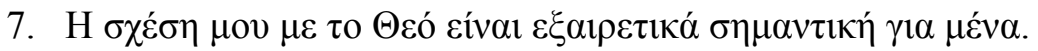

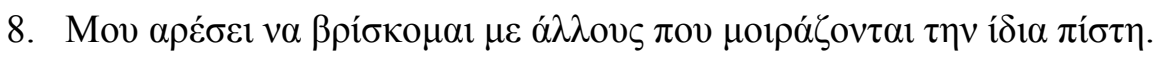

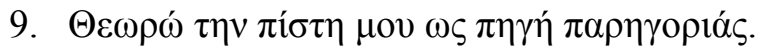

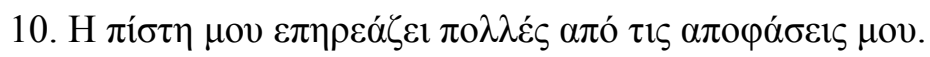

Santa Clara Strength of Religious Faith Questionnaire-SF (in Greek language)

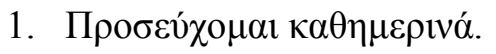

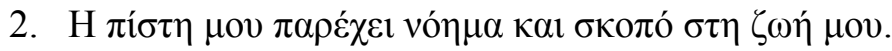

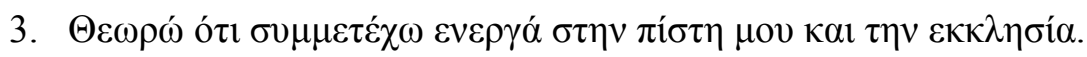

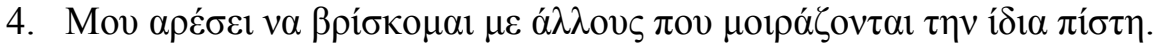

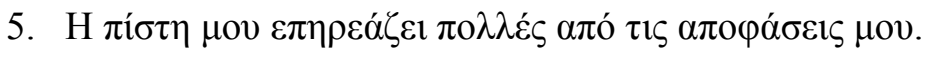

(C) 2014 by the authors; licensee MDPI, Basel, Switzerland. This article is an open access article distributed under the terms and conditions of the Creative Commons Attribution license (http://creativecommons.org/licenses/by/3.0/). 